\title{
Extra Articular Manifestations in Egyptian Rheumatoid Arthritis Patients
}

\author{
Walaa F. El-Baz ${ }^{1}$, Sabila G. Mousa ${ }^{1}$, Naglaa A. Tawfeek ${ }^{1}$, \\ Abeer M. Shawky ${ }^{2}$, Maha M. Ahmed ${ }^{1}$, Rehab A. Mohamed ${ }^{1}$ \\ Departments of Internal Medicine ${ }^{1}$, Cardiology ${ }^{2}$, Al-Azhar University; Egypt
}

\begin{abstract}
Background: Rheumatoid arthritis is a systemic inflammatory disease that can involve other tissues and organs as well as synovial joints. It is characterized by destructive polyarthritis and extra-articular organ involvement, including skin, eye, heart, lung, renal, central and peripheral nervous system and gastrointestinal tract. The extra-articular manifestations of RA can occur at any age. Objectives of this study are to evaluate extra articular manifestations in Egyptian rheumatoid arthritis patients, its relation to the disease activity score (DAS28) and Anti-Cyclic Citrullinated Peptide (ACPA). Methods: This study was conducted on 50 patients they were diagnosed as RA by fulfilling the American College of Rheumatology (ACR) criteria of RA. Their age (mean \pm SD) is $45.78 \pm 13.26$ years. Forty four $(88 \%)$ of them were females, $6(12 \%)$ were males. They were subjected to full medical history and examination, laboratory investigations were done, calculation of DAS28 score, measurement of plasma Anti-Cyclic Citrullinated Peptide (ACPA). RA patients were classified according to DAS 28 into three groups. Results: RA group 1 (mild disease activity) includes $12(24 \%)$ patients with mean \pm SD of DAS 28 was $2.5 \pm 0.55$, group II (moderate disease activity) includes $28(56 \%)$ patients with mean \pm SD of DAS 28 was $3.9 \pm 0.55$ and group III (severe disease activity) includes $10(20 \%)$ patients with mean \pm SD of DAS 28 was $5.35 \pm 0.238$. There was highly significant increase in mean \pm SD of ACPA titer in group III (sever activity), $90.31 \pm 40.78$ $\mathrm{IU} / \mathrm{ml}$ than that of group II $56.48 \pm 27.62 \mathrm{IU} / \mathrm{ml},(\mathrm{p}=0.000)$ and group $1 ; 36.74 \pm 18.95 \mathrm{IU} / \mathrm{ml}$ also mean ACPA in group II increased significantly than that of group I, (P=0.000). Fifty (100\%) RA patients had extra articular manifestations (ExRA); 37 (74\%) had respiratory system disorders, $35(70 \%)$ had hematological manifestations. CVS manifestations were found in $23(46 \%)$. Eye manifestations present in $23(46 \%)$ RA patients. Twelve (24\%) RA patients had skin manifestations. GIT manifestations occur in $11(22 \%)$ patients, $5(10 \%)$ RA patients had renal manifestations. Four $(8 \%)$ RA patients had neurological manifestations. The most common ExRA respiratory disorders was found in 8/12 (66.6\%) patients in group I while it affect $22 / 28(78.5 \%)$ patients in group II and $7 / 10(70 \%)$ patients in group III $(\mathrm{P}=0.000)$ with highly significant changes. Conclusion: This study showed that the ExRA are a common feature in Egyptian RA patients and they are related to the disease activity. [Egypt J Rheumatology \& Clinical Immunology, 2014; 2(1): 71-79]
\end{abstract}

\section{INTRODUCTION}

Rheumatoid arthritis (RA) is the most common systemic inflammatory joint disease, affecting 1-2\% of the population worldwide, with women affected two to three times more common than men ${ }^{1}$. Rheumatoid arthritis can involve other tissues and organs as well as synovial joints with symmetrical involvement of peripheral joints. Hands, feet, and wrists are being most commonly affected. Rheumatoid arthritis can also affect non-articular muscular structures such as tendons, ligaments, and fascia ${ }^{2}$.

Rheumatoid arthritis has a high risk for morbidity and premature death secondary to the earlier development of cardiovascular, lung diseases and malignancy ${ }^{3}$. Extra-articular manifestations of RA are serious conditions and so aggressive treatment and good monitoring for those patients are warranted ${ }^{4}$. Correspondence to Walaa F. El-Baz, Department of Internal Medicine, Al Azhar University; Egypt e-mail:drwalaaelbaz@yahoo.com
Extra-articular manifestations of RA occur in about $40 \%$ of patients, either in the beginning or during the course of their disease ${ }^{5}$, Pulmonary disease is one of the most frequent and the most severe extraarticular manifestations ${ }^{6}$. Patients, who have high titers of rheumatoid factor are most likely to have extra-articular manifestations, including rheumatoid nodules, rheumatoid vasculitis, and pleuro-pulmonary, neurologic, digestive, cardiovascular, cutaneous, hematologic, and ocular complications ${ }^{7,8}$.

\section{PATIENTS AND METHODS}

This is a cross sectional observational study that was conducted on 50 patients they were diagnosed as RA, fulfilling the ACR criteria ${ }^{9}$. They were selected from internal medicine department, internal medicine outpatient clinic, Al Zahraa university hospital. Their age ranged between 35- 60 years with mean \pm SD of $45.78 \pm 13.26$ year. Forty four $(88 \%)$ of them were 
females, $6(12 \%)$ of them were male and $4 / 6$ patients were smokers. The duration of the disease ranged from 1 to 35 years with mean \pm SD of $10.98 \pm 7.45$ years.

All patients were submitted to:

1- Full medical history and clinical examination with special concern to musculoskeletal system examination to detect any extra articular manifestations.

2- Determination of disease activity according to DAS 28.

The DAS 28 is calculated as follows:

$0 . S 528=0.56 \times \sqrt{T E N 28}+0.28 \times \sqrt{S W 28}+0.70 \times \ln (E S R)+0.014 \times S A$

The DAS 28 activity evaluation (10):

DAS28 $\geq 5.1=$ high disease activity

DAS $>3.2<5.1=$ moderate disease activity

DAS2 $>2.6<3.2=$ low disease activity

DAS2 $8<2.6=$ remission

3- Laboratory tests were done including the following:

- Complete blood count (CBC).

- Liver function tests including: (Serum AST, ALT, Serum albumin, Serum bilirubin)

- Kidney function tests including:

- Blood urea, Serum creatinine.

- Urine analysis for presence or absence of proteinuria or hematuria.

- Inflammatory markers including:

- ESR (male; 0-20 mm/h, female; 0-30 $\mathrm{mm} / \mathrm{hr}$ ).

- $\quad$ CRP (normal $<6 \mathrm{mg} / \mathrm{dl}$ ) to assess disease activity positive result $>6 \mathrm{mg} / \mathrm{dl}$.

- Immunological studies:

Rheumatoid factor (RF) The RF was analyzed by latex agglutination test, according to the manufacturer's instructions (with a cut-off titer $\geq 8 \mathrm{IU} / \mathrm{ml}$ ) for a positive test.

\section{Plasma Anti-Cyclic Citrullinated Peptide (ACPA): \\ ACPA was determined by ELISA} (QUANTA Lite CCP3 IgG ELISA) with cut-off value for a positive test $\geq 20 \mathrm{IU} / \mathrm{ml}$

\section{Measurement of plasma Anti-Cyclic Citrullinated Peptide (ACPA): Principle of Procedure:}

The Antigen used in the QUANTA Lite ${ }^{\mathrm{TM}}$ CCP3 IgG ELISA test is a synthetic, cyclic citrullinated peptide that was found to have high sensitivity and specificity in detecting antibodies in patients with RA. This antigen is bound to the surface of a micro-well plate. Pre-diluted patient samples are added to separate wells, allowing any CCP IgG antibodies present to bind to the immobilized Antigen. Unbound sample is washed away and an enzyme labeled Antihuman IgG conjugate is added to each well. A second incubation allows the enzyme labeled Anti-human IgG to bind to any patient antibodies that have become attached to the micro-wells. After washing away any unbound enzyme labeled anti- human IgG, the remaining enzyme activity is measured by adding a chromogenic substrate and measuring the intensity of the color that develops.

4- Conventional radiology: All patients were examined radiologically by plain $\mathrm{x}$ ray chest, $\mathrm{x}$ ray both hands and for any other affected joints.

5- Eye and fundus were examination by ophthalmologist colleagues.

6- Pulmonary functions tests: to measure FEV, FVC to diagnose the patients with obstructive or restrictive lung disease.

7- $\quad$ Echocardiography (by VIVID 7 Apparatus).

\section{Statistical Analysis}

Data were analyzed by Microsoft office 2003 (excel) and Statistical Package for Social Science (SPSS) version 16. In descriptive analysis, the parameters such as mean, and standard deviation (SD) were reported. The analytical procedures were performed using statistical tests.

\section{RESULTS}

Fifty patients with established rheumatoid arthritis, their age ranged between 35- 60 years with mean \pm SD of $45.78 \pm 13.26$ year. Forty four $(88 \%)$ of them were females, $6(12 \%)$ were males and $4 / 6$ patients are smokers. The duration of the disease ranged from 1 to 35 years with mean $\pm \mathrm{SD}$ of $10.98 \pm 7.45$ years (Table 1$)$.

Clinical evaluation of RA patients showed that all patients had tender joints, the number of tender joints ranged from 3-10 joints with mean $\pm \mathrm{SD}$ of $6.2 \pm 2.2$ joints while $45(90 \%)$ of RA patients suffered from swollen joints, their number ranged from 2-9 joints with mean \pm SD of $5.3 \pm 1.7$ joints. Affection of small joints more than the big joints, nineteen $(38 \%)$ patients had morning stiffness that ranged from 10-90 minutes with mean $\pm \mathrm{SD}$ of $48.7 \pm 25.06$ minutes. Interestingly all 50 RA patients had ExRA, constitutional symptoms as fever, fatigue, weight loss and anemia were present in 9 patients (Table 2).

Laboratory findings of 50 RA patients were as shown in Table (3). 
As regard the inflammatory markers, The ESR level ranged from $13-150 \mathrm{~mm} / \mathrm{h}$ with mean $\pm \mathrm{SD}$ of $66.1 \pm 36.3 \mathrm{~mm} / \mathrm{h}$, RF were +ve in $44(88 \%)$ patients, CRP were positive in $38(76 \%)$ patients. ACPA titer was positive in $44(88 \%)$ of RA patients, it ranged from $5.5-149 \mathrm{IU} / \mathrm{ml}$ with a mean \pm SD of $58.5-33.6$ $\mathrm{IU} / \mathrm{ml}$ (Table 4 and Figure 1).

RA patients were classified according to Disease Activity Score 28 (DAS 28) into three groups: group 1 (mild activity) includes $12(24 \%)$ patients with mean \pm SD of DAS 28 was $2.5 \pm 0.55$, group II (moderate activity) includes $28(56 \%)$ patients with mean \pm SD of DAS 28 was $3.9 \pm 0.55$ and group III (severe activity) includes $10(20 \%)$ patients with mean \pm SD of DAS 28 was $5.35 \pm 0.238$ (Table 5 and Figure 2).

RF: RF was found to be positive in $11(91.6 \%)$ RA patients in group I, $24(85.7 \%)$ in group II, and 9 $(90 \%)$ in group III. No significant differences between the three groups $(\mathrm{p}>0.05)$ (Table 6).

CRP: Ten $(83.3 \%)$ patients had positive CRP in group I, $22(78.5 \%)$ patients had positive CRP in group II, while $6(60 \%)$ had positive CRP in group III so there were no significant changes between those groups $(\mathrm{P}>0.05$ ) (Table 6).

ESR: There was significant increase in mean \pm SD level of ESR $(99 \pm 46.30) \mathrm{mm} / \mathrm{h}$ in group III than that of group I $(73.3 \pm 24.9) \mathrm{mm} / \mathrm{h}$, also mean \pm SD of ESR in group I increased significantly than group II $(58.1 \pm 37.9) \mathrm{mm} / \mathrm{h}(\mathrm{P}<0.05)$ (Table 6).

ACPA: There was highly significant increase in mean \pm SD of ACPA titer in group III RA patients $90.31 \pm 40.78 \mathrm{IU} / \mathrm{ml}$ than that of group II patients $56.48 \pm 27.62 \mathrm{IU} / \mathrm{ml},(\mathrm{p}=0.000)$ also mean ACPA in group II increased significantly than that of group I $36.74 \pm 18.95 \mathrm{IU} / \mathrm{ml}(\mathrm{P}=0.000)$ (Table 6 and Figure 3$)$.

Interestingly it was found that all RA patients had some sort of extra articular manifestations that may involve one or more systems.

1- Neurological manifestations: Four (8\%) RA patients had neurological manifestations in the form of carpal tunnel syndrome (2\%) and peripheral neuropathy (6\%) (Table 7).

2- Cardio vascular system (CVS): CVS manifestations were found in $23(46 \%) \mathrm{RA}$ patients in the form of valve diseases $(28 \%)$, Heart failure (12\%), dilated cardiomyopathy $(4 \%)$ and ischemic heart disease (2\%) (Table 7).

3- Gastro-intestinal tract (GIT): GIT manifestations occur in 11 (22\%) RA patients in the form of gastritis $(16 \%)$, peptic ulcer $(6 \%)$. These manifestations may be due to drug induced side effects (Table 7).

4- Respiratory manifestations: Thirty seven (74\%) RA patients had respiratory system disorder and they suffered from interstitial pulmonary disease (IPD) (30\%), COPD (16\%), pleural effusion (16\%), pleurisy $(8 \%)$ and Caplan's syndrome (2\%) (Table 7).

5- Hematological manifestations: Thirty five (70\%) RA patients had hematological manifestations in the form of anemia (44\%), thrombocytopenia (8\%) with mean value; $78.25 / \mathrm{mm}^{3}$, thrombocytosis $(4 \%)$ with a mean value; $484 / \mathrm{mm}^{3}$, leucopenia $(2 \%)$ and leucocytosis (10\%), Felty' syndrome (2\%) (Table 7).

6- Renal manifestations: Five (10\%) RA patients had renal manifestations in the form of proteinuria (8\%), hematuria (2\%) (Table 7).

7- Skin manifestations: Twelve (24\%) RA patient had skin manifestations in the form of rheumatoid nodule $(8 \%)$, skin pigmentations $(16 \%)$, no patients had vasculitic skin rash (Table 7).

8- Eye manifestations: Twenty three (46\%) RA patients had kerato- conjunctivitis sicca $(30 \%)$, ulcerative keratitis $(10 \%)$, episcleritis $(6 \%)$ (Table 7 and Figure 4).

\section{Extra articular manifestations of $50 \mathrm{RA}$ patients showed that:}

Respiratory system: Respiratory disorder were found in $8 / 12(66.6 \%)$ patients in group I while it affect 22/28 (78.5\%) patients in group II (the highest incidence being in group II RA patients) and $7 / 10$ $(70 \%)$ patients in group III RA patients $(\mathrm{P}=0.000)$ with highly significant changes (Table 8).

Hematological: Hematological disorders were found in 9/12 (75\%) patients in group I while it affect only $16 / 28(57.1 \%)$ of RA patients in group II and $9 / 10$ (90\%) patients in group III $(\mathrm{P}=0.000)$ these changes were highly significant (Table 8).

Ocular manifestations: These were found in $4 / 12(33.3 \%)$ patients in group I while it affect $14 / 28$ $(50 \%)$ patients in group II and 5/10 (50\%) patients in group III $(\mathrm{P}=0.001)$ this is a statistically highly significant (Table 8).

CVS: CVS disorders were found in 5/12 (41.6\%) patients in group I while it affect $13 / 28(46.4 \%)$ patients in group II and 5/10 (50\%) of RA patients in group III $(\mathrm{P}=0.004)$, these indicates a statistically significant higher incidence of cardiovascular disorders in group III patients than that of group I or II (Table 8).

Skin: Skin disorders were found in 2/12 (16.6\%) patients in group I while it affect $7 / 28(25 \%)$ patients in group II and $3 / 10(30 \%)$ patients in group III this was found to be a statistically significant $(\mathrm{P}=0.024)$ changes (Table 8).

GIT: GIT disorders were found in only $1 / 12$ $(8.3 \%)$ patient in group I while it affect $7 / 28(25 \%)$ of RA patients in group II and $3 / 10(30 \%)$ patients in group III $(\mathrm{P}=0.044)$, these changes were statistically significant (Table 8). 
Renal: Renal disorders were found in $3 / 28$ $(10.7 \%)$ patients in group II and 2/10 (20\%) patients in group III, no renal disorder was found in group I patients $(\mathrm{P}=0.32)$, these changes were non significant (Table 8).
Neurological disorders were found in $2 / 12$ $(16.6 \%)$ patients in group I while it affect $1 / 28(3.5 \%)$ patients in group II and $1 / 10(10 \%)$ patients in group III, this was statistically non significant $(\mathrm{P}=0.23)$ (Table 8).

Table 1. Demographic data of 50 RA patients.

\begin{tabular}{|c|c|c|}
\hline Parameter & Range & Mean \pm SD \\
\hline Age (year) & $35-60$ & $45.78 \pm 13.26$ \\
\hline $\operatorname{Sex}(M / F)$ & ----- & $6 / 44 \quad 12 \% / 88 \%$ \\
\hline Duration of the disease (year) & $1-35$ & $10.98 \pm 7.45$ \\
\hline
\end{tabular}

Table 2. The main clinical manifestations of 50 RA patients.

\begin{tabular}{lccc}
\hline \multicolumn{1}{c}{ Parameter } & Number of patients & Range & Mean \pm SD \\
\hline Tender joints & $50(100 \%)$ & $3-10$ & $6.24 \pm 2.24$ \\
Swollen joint & $45(90 \%)$ & $2-9$ & $5.34 \pm 1.75$ \\
Morning stiffness & $19(38 \%)$ & $10-90 \mathrm{~m}$ & $19.68 \pm 27.5$ \\
ExRA & $50(100 \%)$ & ----- & ------- \\
\hline
\end{tabular}

Table 3. Laboratory data of 50 RA patients.

\begin{tabular}{lcc}
\hline & Parameter & Mean \pm SD \\
\hline WBCs $/ m^{3}$ & $7.72 \pm 3.92$ \\
HB g/dl & $11.5 \pm 1.6$ \\
PLT $/ m^{3}$ & $254 \pm 102.4$ \\
Urea $m g / d l$ & $28.7 \pm 14.7$ \\
Creatinine $m g / d l$ & $0.71 \pm 0.39$ \\
AST I u/l & $28.38 \pm 20.66$ \\
ALT $i . u l l$ & $22.74 \pm 13.61$ \\
Albumin $\mathrm{g} / \mathrm{dl}$ & $3.94 \pm 0.29$ \\
Bilirubin $m g / d l$ & $0.44 \pm 0.28$ \\
\hline
\end{tabular}

Table 4. RF, CRP and ACPA, ESR of 50 RA patients.

\begin{tabular}{lcccc}
\hline \multicolumn{1}{c}{ Parameter } & Positive & Negative & Range & Mean \pm SD \\
\hline RF IU/ml & $44(88 \%)$ & $6(12 \%)$ & ----- & ----- \\
CRP $\mathrm{mg} / \mathrm{dl}$ & $38(76 \%)$ & $12(44 \%)$ & ----- & ----- \\
ACPA $(\mathrm{IU} / \mathrm{ml})$ & $44(88 \%)$ & $6(12 \%)$ & $5.5-149$ & $58.5 \pm 33.6$ \\
ESR $(\mathrm{mm} / \mathrm{h})$ & ---- & ---- & $13-150$ & $66.1 \pm 36.3$ \\
\hline
\end{tabular}


El-Baz, et al.: Extra articular manifestations in Egyptian RA patients

Table 5. Classification of RA patients according to DAS -28 score.

\begin{tabular}{|c|c|c|}
\hline DAS score & Number of patients & Mean \pm SD \\
\hline Group I & $12(24 \%)$ & $2.51 \pm 0.55$ \\
\hline Group II & $28(56 \%)$ & $3.93 \pm 0.55$ \\
\hline Group III & $10(20 \%)$ & $5.35 \pm 0.238$ \\
\hline
\end{tabular}

Table 6. RF, CRP, ESR, ACPA in 50 RA patients with different disease activity scores (DAS 28).

\begin{tabular}{lcccc}
\hline \multicolumn{1}{c}{ Parameter } & Mild & Moderate & Severe & Sig. \\
\hline RF positivity & $11(91.6 \%)$ & $24(85.7 \%)$ & $9(90 \%)$ & Non Sig. \\
CRP positivity & $10(83.3 \%)$ & $22(78.5 \%)$ & $6(60 \%)$ & Non Sig. \\
ESR (Mean \pm SD) & $73.3 \pm 24.9$ & $58.1 \pm 37.9$ & $99 \pm 64.30$ & Sig. \\
ACPA (Mean \pm SD) & $36.74 \pm 18.95$ & $56.48 \pm 27.62$ & $90.31 \pm 40.78$ & Highly Sig. \\
\hline P $>0.05$ Non Sig $. \quad \mathrm{P}<0.05$ Sig.,
\end{tabular}

$\mathrm{P}>0.05$ Non Sig., $\quad \mathrm{P}<0.05$ Sig., $\quad \mathrm{p}<0.001$ Highly Sig.

Table 7. The extra articular manifestations of RA patients.

\begin{tabular}{|c|c|c|}
\hline System affected & Number of patients & Lesions \\
\hline Neurological & $4(8 \%)$ & Carpal tunnel (2\%) - peripheral neuropathy $(6 \%)$. \\
\hline CVS & $23(46 \%)$ & Valve disease (28\%) - (IHD2\%) - HF(12\%) - cardiomyopathy (4\%). \\
\hline GIT & $11(22 \%)$ & Gastritis (16\%)- peptic ulcer (6\%). \\
\hline Respiratory & $37(74 \%)$ & $\begin{array}{l}\text { IPD }(30 \%) \text { - COPD (16\%) - effusion (16\%) - pleurisy (8\%) - } \\
\text { Caplan's syndrome }(2 \%) .\end{array}$ \\
\hline Hematological & $35(70 \%)$ & $\begin{array}{l}\text { Anemia }(44 \%) \text { - Thrombocytopenia }(8 \%) \text { - Thrombocytosis }(4 \%) \text { - } \\
\text { leucopenia }(2 \%) \text { - leucocytosis }(10 \%) \text {, Felty' syndrome }(2 \%) \text {. }\end{array}$ \\
\hline Renal & $5(10 \%)$ & Proteinuria $(8 \%)$ - hematuria $(2 \%)$. \\
\hline Skin & $12(24 \%)$ & $\begin{array}{l}\text { Rheumatoid nodule } \\
(8 \%) \text { - skin pigmentations }(16 \%) \text {. }\end{array}$ \\
\hline Ocular & $23(46 \%)$ & $\begin{array}{l}\text { Kerato-conjunctivitis sicca (30) - ulcerative keratitis (10\%) - } \\
\text { episcleritis }(6 \%) \text {. }\end{array}$ \\
\hline
\end{tabular}

Table 8.Comparison between the three groups of RA patients regarding the extra articular manifestations.

\begin{tabular}{lccccc}
\hline \multicolumn{1}{c}{ Parameter } & $\begin{array}{c}\text { Group I } \\
\text { Mild Activity } \\
(\mathbf{N = 1 2})\end{array}$ & $\begin{array}{c}\text { Group II } \\
\text { Moderate Activity } \\
(\mathbf{N = 2 8})\end{array}$ & $\begin{array}{c}\text { Group III } \\
\text { Sever Activity } \\
(\mathbf{N = 1 0})\end{array}$ & P-value & Sig. \\
\hline Respiratory & $8(66.6 \%)$ & $22(78.5 \%)$ & $7(70 \%)$ & 0.000 & H.S \\
Hematological & $9(75 \%)$ & $16(57.1 \%)$ & $9(90 \%)$ & 0.000 & H.S \\
Eye & $4(33.3 \%)$ & $14(50 \%)$ & $5(50 \%)$ & 0.001 & H.S \\
CVS & $5(41.6 \%)$ & $13(46.4 \%)$ & $5(50 \%)$ & 0.004 & H.S \\
Skin & $2(16.6 \%)$ & $7(25 \%)$ & $3(30 \%)$ & 0.024 & S \\
GIT & $1(8.3 \%)$ & $7(25 \%)$ & $3(30 \%)$ & 0.044 & S \\
Renal & ----- & $3(10.7 \%)$ & $2(20 \%)$ & 0.322 & N.S \\
Neurological & $2(16.6 \%)$ & $1(3.5 \%)$ & $1(10 \%)$ & 0.233 & N.S \\
\hline
\end{tabular}


El-Baz, et al.: Extra articular manifestations in Egyptian RA patients

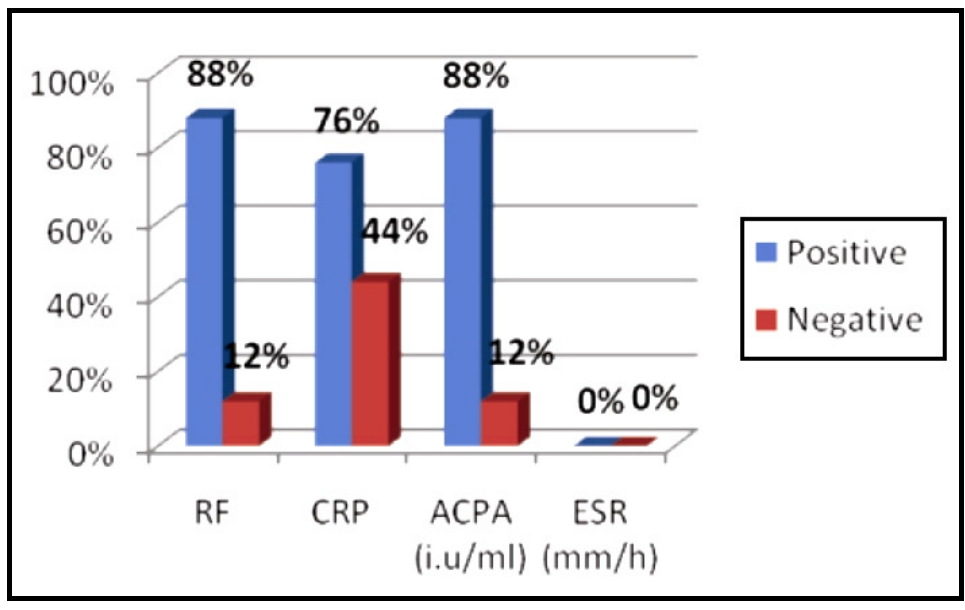

Figure 1. Frequency of RF, CRP and ACPA in 50 RA patients.

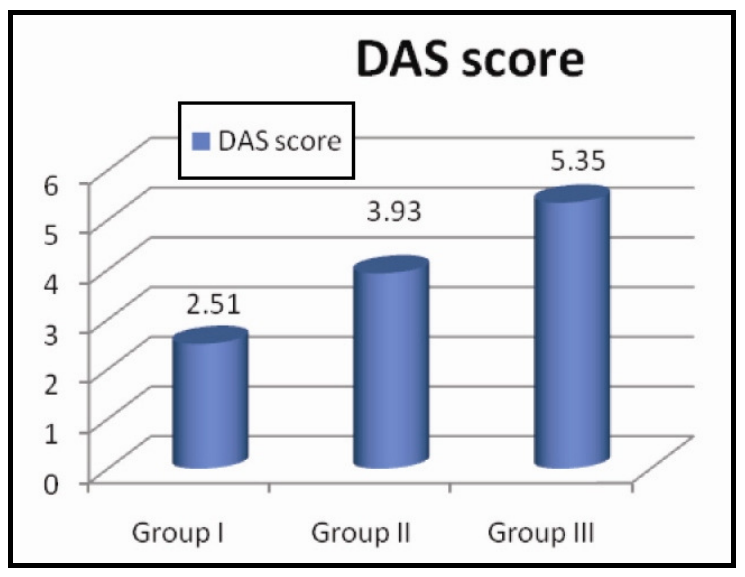

Figure 2. Classification of 50 RA patients according to DAS score.

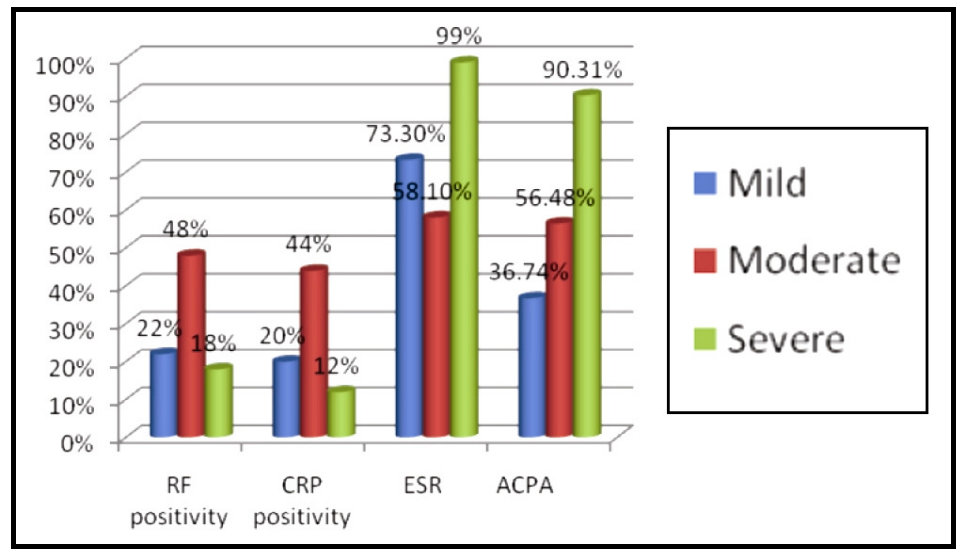

Figure 3. RF, CRP, ESR, ACPA in 50 RA patients with different disease activity scores (DAS 28). 


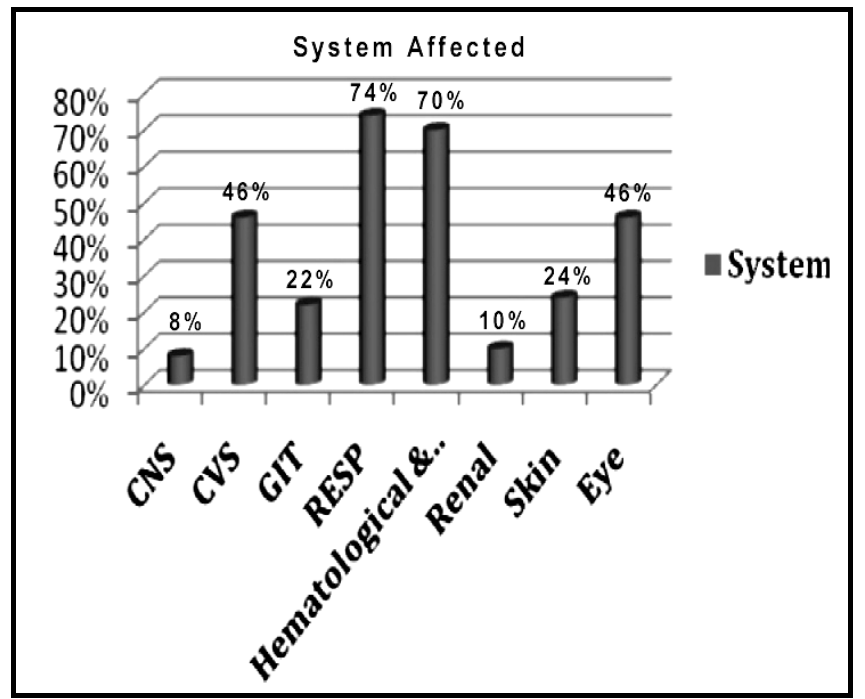

Figure 4. The extra articular manifestations of 50 RA patients.

\section{DIscussion}

Rheumatoid arthritis (RA) is a systemic autoimmune disease whose main characteristic is persistent joint inflammation that results in joint damage and loss of function. It is characterized by destructive polyarthritis and extra-articular organ involvement, including the skin, eye, heart, lung, renal, nervous and gastrointestinal systems ${ }^{11}$. Although RA is more common in females, extra-articular manifestations of the disease are more common in males. The extra-articular manifestations of RA can occur at any age after onset. The frequency of extra-articular manifestations in RA differs according studied population. Extra-articular organ involvement in RA is more frequently seen in patients with severe, active disease and is associated with increased mortality ${ }^{11}$.

This study showed that the women were affected more than men with rheumatoid arthritis, these results as the usual epidemiology of RA that affect women more than men and in middle age. These results were approved also by Helmick et al. ${ }^{12}$, DiGiuseppe et al. ${ }^{13}$ and Bope ${ }^{14}$. The higher prevalence of autoimmunity in women suggests that sex hormones might play a role in susceptibility. Estrogen is thought to exert a biphasic dose effect; lower levels enhance while high levels inhibit specific immune-activities whereas progesterone promotes the development of Th2 cells which inhibits the proliferation of the Th1 cells ${ }^{15}$. Pregnancy is associated with a marked increase of estrogen, progesterone and cortisol in the plasma and brings about remission in autoimmune disorders such as RA and multiple sclerosis which are both driven by Th1 cytokines ${ }^{16}$. The present study showed that ACPA was found in $88 \%$ of RA patients however, Sakineh-Khatoun et al. ${ }^{17}$, had studied 136 RA patients and 184 controls, they found that the sensitivity of ACPA was $62.5 \%$ of patients with a specificity of $89.1 \%$. The sensitivity of RF was $85.3 \%$. The specificity was $64.7 \%$. ACPA is more specific than RF in the diagnosis of RA.

Our results revealed that there was increased plasma level of ACPA in RA patients with ExRA. These results are similar to the study of Turesson and his colleagues ${ }^{18}$ as they found that ACPA tend to be higher in patients with ExRA. Our results revealed that RF tended to be positive in ACPA positive patients. These results were previously reported by Nishimura et al. ${ }^{19}$, Papadopoulos et al. ${ }^{20}$ and Onder et al. ${ }^{21}$.

The present study showed strong relationship between disease activity and ACPA titer as it showed higher levels in RA patients with severe disease activity $\&$ low levels in patients with mild disease activity, this agrees with the results of Papadopoulos et al, (20) \& Onder et al. $^{21}$, showed that the majority of ACPA + ve patients exhibited more active disease with higher DAS 28 score $^{22}$. Eltouky et al. $^{23}$, showed significant increase in mean serum level of ACPA in patient with than in patients without ExRA manifestations.

Interestingly, in the present study all RA patients had extra articular manifestations specially the respiratory system affection which was found in $74 \%$ of our RA patients. A previous study of Youssef et al. ${ }^{6}$ that included 36 RA patients, they have found that about $64 \%$ of RA 
patients had abnormal pulmonary function tests (PFT), they concluded that pulmonary involvement is a common manifestation in Egyptian RA patients with mixed obstructive and restrictive pattern. The present study showed hematological involvement in $68 \%$ of RA patients, ocular \& cardiovascular manifestations were equally found in $46 \%$ of patients, skin involvement was found in $24 \%$ of RA patients, GIT involvement was found in $22 \%$ and renal involvement was found in $10 \%$ of patients. The least common ExAR was the neurological manifestations: Peripheral neuritis or mononeuritis multiplex that was found in only $8 \%$ of RA patients. However, Hochberg et al. $^{24}$ have studied 140 patients with definite RA, Anemia occurred in $61 \%$, thrombocytosis in $16 \%$, pulmonary involvement in $10 \%$, and renal amyloidosis, vasculitis and Felty' syndrome were present in $6 \%, 2 \%$ and $1 \%$, respectively. Hence anemia, thrombocytosis and respiratory system involvement were the most common ExAR manifestation. Moreover, in agreement with our results, Brown $^{25}$ has found that the ExRA are dominated by pulmonary, cardiac and vascular changes.

In our study, regarding the hematological ExRA anemia was the most common either normocytic normochromic anemia or microcytic hypochromic anemia and we have found only one patient with Felty' syndrome. Inspite the fact that thrombocytosis is a common feature in active RA patients, unexpectedly thrombocytopenia was more common than thrombocytosis, in our RA patients this might be explained by a side effect of prolonged immunesuppression or associated HCV infection. While, Citation and Rehman ${ }^{26}$, have found that anemia and thrombocytosis are more common than thrombocytopenia in RA patients.

\section{Conclusion}

Our study showed that the ExRA are common in Egyptian RA patients they are more common in males than females. ExRA are positively correlated with the disease activity and the presence of ACPA. The most common are respiratory \& hematological manifestations, the least are the renal and neurological manifestations. RA should be diagnosed early and treated aggressively not only for the sake of the joints, but also to prevent ExRA manifestations that will increase the RA morbidity \& mortality.

[Disclosure: Authors report no conflict of interest]

\section{REFERENCES}

1. Turesson C, Matterson EL: Management of extraarticular disease manifestations in rheumatoid arthritis. Curr Opin Rheumatol. 2004; 16(3): 206-211.
2. Mielants H, Van den Bosch F: Extra-articular manifestations. Clin Exp Rheumatology. 2009; 27(Suppl 55): S56-S61.

3. Crostein BN: Interleukin-6 - a key mediator of systemic and local symptoms in rheumatoid arthritis. Bull NYU Hosp J Dis. 2007; 65(Suppl 1): S11-S15.

4. Young A, Koduri G: Extra-articular manifestations and complications of rheumatoid arthritis. Best Pract Res Clin Rheumatol. 2007; 21(5): 907-927.

5. Cimmino MA, Salvrani C, Macchioni P: extra articular manifestation in 587 Italian patients with rheumatoid arthritis. Rheumatol Int. 2000; 19(6): 213-217.

6. Youseff AA, Machaly SA, Dosoky ME: Respiratory symptoms in rheumatoid arthritis: correlation to pulmonary abnormalities detected by high resolution computed tomography and pulmonary function testing. Rheumatol Int. 2012; 32(7): 1985-95.

7. Gabriel SE, Crowson CS, Kremers HM, et al: Survival in rheumatoid arthritis: a population-based analysis of trends over 40 years arthritis Rheum.2003; 48(1): 54-58.

8. Turesson C, wey and CM, Matteson EL: Genetics of Rheumatoid arthritis.Is there a pattern predicating extrarticular manifestation? Arthritis Rheum 2004; 51(5): 853-863.

9. Arnett FC, Edworthy SM, Bloch DA et al: The American Rheumatism Association revised criteria for the classification of rheumatoid arthritis. Arthritis Rheum. 1988; 31: 315.

10. NICE: Adalimumab, etanercept and infliximab for the treatment of rheumatoid arthritis 2007.

11. Manole Cojocaru, Inimioara Mihaela Cojocaru, Isabela Silosi, Camelia Doina Vrabie, and $\mathrm{R}$ Tanasescu: Extra-articular Manifestations in Rheumatoid Arthritis Maedica (Buchar). 2010; 5(4): 286-291.

12. Helmick CG, Felson DT, Lawrence RC, et al: National Arthritis Data, Workgroup. "Estimates of the prevalence of arthritis and other rheumatic conditions in the United States. Part I". Arthritis and rheumatism; 200858 (1): 15-25.

13. Di Giuseppe D, Alfredsson L, Bottai M, et al: Long term alcohol intake and risk of rheumatoid arthritis in women: a population based cohort study. BMJ. 2012; 10; 345: e4230.

14. Bope ET: Conn's Current Therapy. Philadelphia, $\mathrm{Pa}$.: Saunders Elsevier; http:// www. mdconsult. $\mathrm{com} /$ books/ about. do? about $=$ true\&eid $=$ \$eid\&isbn=978-1-4557-02954\&uniqId=398813857-1936.Accessed 2013. 26.

15. Whitacre CC, Reingold SC, O'Looney PA et al: A gender gap in autoimmunity. Science. 1999; 283: 1277-8.

16. Al-Shamri S, Rawoot P, Azizieh F, et al: Th1/Th2 cytokine patterns and clinical profiles during and after pregnancy in women with multiple sclerosis. $\mathbf{J}$ Neurol Sci. 2004; 222: 21-7. 
17. Sakineh-Khatoun S, Shahin E, Gharibdoost F et al: International journal of rheumatic diseases. Article first published online. 2007; 15 DOI: 10.1111/j.1479-8077.00272.

18. Turesson C, JacobssonL T, Sturfelt G, et al: Rheumatoid factor and antibodies to cyclic citrullinated peptides are associated with sever eextra-articular manifestations in rheumatoid arthritis. Ann Rheum Dis. 2006; 66(1): 59-64.

19. Nishimura K, Sugiyama D, Kogata Y, et al: "Metaanalysis: diagnostic accuracy of anti-cyclic citrullinated peptide antibody and rheumatoid factor for rheumatoid arthritis". Annals of Internal Medicine. 2007; 146 (11): 797-808. PMID 17548411.

20. Papadopoulos NG, Tsiaousis GZ, Pavlitou-Tsiontsi $A$ et al: Does the Presence of Anti-CCP Autoantibodies and Their Serum Levels Influence the Severity and Activity in Rheumatoid Arthritis Patients? Clin Rev Allergy Immunol. 2008; 34(1): 11- 5 .

21. Onder B, Kurtaran A, Kimyon S, et al: Association of anti-CCP positivity with serum ferritin and DAS28. Rheumatol Int. 2009; 30(2):223-7.
22. Niewold TB, Harrison MJ and Paget SA: Anti$\mathrm{CCP}$ antibody testing as a diagnostic and prognostic tool in rheumatoid arthritis. QJM: An International Journal of Medicine. 2007; 100 (4): 193-201; available at http: // qjmed. oxfordjournals. org/misc/terms.shtml

23. Eltokhy M H, Ali T S, Abd rabo A S, Gad M A, El Sawi A H, EL-Ghaffar A N, Mansour A M: relationship between anti-cyclic citrullinated peptide antibodies and disease activity and extra-articular manifestations of rheumatoid arthritis in Egyptian patient. Al-azhar assiut medical journal, 2011; 9: 1.

24. Hochberg MC, Johnston SS, John AK, et al: The incidence and prevalence of extra-articular and systemic manifestations in a cohort of newly diagnosed patients with rheumatoid arthritis between 1999 and 2006. Curr Med Res Opin. 2008; 24(2): 469-480.

25. Brown KK: Roger S. Mitchell Lecture; Rheumatoid Lung Disease. Proc Am Thorac Soc. 2007; 4: 443 448, Internet address: www.atsjournals.org.

26. Citation $\mathrm{H}$ and Rehman: Hemolytic Anemia following Mycoplasma infection. The internet journal of hematology. 2008; $4: 1$. 